University of Nebraska - Lincoln

DigitalCommons@University of Nebraska - Lincoln

1993

\title{
Photosynthesis and Stomatal Conductance Related to Reflectance on the Canopy Scale
}

\author{
S. B. Verma \\ University of Nebraska - Lincoln
}

Follow this and additional works at: https://digitalcommons.unl.edu/natrespapers

Part of the Natural Resources and Conservation Commons, Natural Resources Management and Policy Commons, and the Other Environmental Sciences Commons

Verma, S. B., "Photosynthesis and Stomatal Conductance Related to Reflectance on the Canopy Scale" (1993). Papers in Natural Resources. 1207.

https://digitalcommons.unl.edu/natrespapers/1207

This Article is brought to you for free and open access by the Natural Resources, School of at DigitalCommons@University of Nebraska - Lincoln. It has been accepted for inclusion in Papers in Natural Resources by an authorized administrator of DigitalCommons@University of Nebraska - Lincoln. 


\section{Photosynthesis and Stomatal Conductance Related to Reflectance on the Canopy Scale*}

S. B. Verma,${ }^{\dagger}$ P. J. Sellers,${ }^{\ddagger}$ C. L. Walthall,${ }^{\S}$ F. G. Hall,${ }^{\ddagger} J$. Kim,${ }^{\dagger}$ and S. J. Goetz

${ }^{\dagger}$ Department of Agricultural Meteorology, University of Nebraska, Lincoln, ${ }^{\ddagger}$ Code 923, NASA, Goddard Space Flight Center, Greenbelt, ${ }^{\S}$ The Laboratory for Global Remote Sensing Studies, Department of Geography, University of Maryland, College Park

$F_{i}$ Hield measurements of carbon dioxide and water vapor fluxes were analyzed in conjunction with reflectances obtained from a helicopter-mounted Modular Multiband Radiometer (MMR) at a grassland study site during the First ISLSCP (International Satellite Land Surface Climatology Project) Field Experiment (FIFE). These measurements are representative of the canopy scale and were made over a range of meteorological and soil moisture conditions during different stages in the annual life cycle of the prairie vegetation, and thus provide a good basis for investigating hypotheses/relationships potentially useful in remote sensing applications. We tested the hypothesis (Sellers, 1987) that the simple ratio vegetation index (SR) should be near-linearly related to the derivatives of the unstressed canopy stomatal conductance $\left(g_{c}^{*}\right)$ and the unstressed canopy photosynthesis $\left(P_{c}^{*}\right)$ with respect to photosynthetically active radiation (PAR). Even though there is some scatter in our data, the results seem to support this hypothesis. Further investigation, however, is needed before such relationships can be employed in satellite remote sensing applications.

* Published as Paper No. 9650, Journal Series, Agricultural Research Division, University of Nebraska, Lincoln.

Address correspondence to Shashi B. Verma, Dept. of Agricultural Meteorology, Univ. of Nebraska, P.O. Box 830728, Lincoln, NE 68583-0728.

Received 7 January 1992; revised 22 August 1992.

\section{INTRODUCTION}

In recent years many researchers (e.g., Monteith, 1977; Tucker et al., 1981; Asrar et al., 1984; Sellers, 1985 ; 1987) have investigated the relationships between linear combinations of reflected visible and near infrared radiation (known as vegetation indices) and biophysical quantities such as the leaf area index, biomass, and the amount of photosynthetically active radiation (PAR) absorbed by the canopy. Two vegetation indices commonly used are:

simple ratio vegetation index $(\mathrm{SR})=R_{N} / R_{v}$

and

normalized difference vegetation index (NDVI)

$$
=\left(R_{N}-R_{v}\right) /\left(R_{N}+R_{v}\right) \text {, }
$$

where $R_{N}$ and $R_{v}$ are upwelling radiances or surface reflectances in the near-infrared and visiblered spectral regions, respectively.

Canopy conductance $\left(g_{c}\right)$ can be described using a simple multiplicative relationship (e.g., Jarvis, 1976; Stewart, 1988):

$$
g_{c}=g_{c}^{*}(P A R) \cdot\left[f(T) \cdot f(D) \cdot f\left(\theta_{s}\right)\right] .
$$

Similarly, canopy photosynthesis $\left(P_{c}\right)$ can be described as (e.g., Sellers, 1987):

$$
P_{c}=P_{c}^{*}(P A R) \cdot\left[h(T) \cdot h(D) \cdot h\left(\theta_{s}\right)\right] .
$$


The terms $g_{c}^{*}$ (PAR) and $P_{c}^{*}$ (PAR) are the unstressed values of $g_{c}$ and $P_{c}$, regulated only by vegetation type, health, density, and the amount of incoming PAR. The "stress factors" $f(x)$ and $h(x)$ account for the effects of temperature $(T)$, ambient vapor pressure deficit $(D)$, and extractable soil water $\left(\theta_{s}\right)$. The stress factors vary between unity (optimal conditions) and zero (unfavorable conditions shutting down photosynthesis and transpiration). The stress factors operating on $g_{c}$ and $P_{c}$ are assumed to be invariant within the canopy for a given set of environmental conditions. In this study, canopy level flux data measured at the site were used to obtain the functional forms of the expressions for the stress factors (see Appendix A). The derived coefficients for these stress factors are independent of the time-varying leaf area index.

The terms $g_{c}^{*}$ and $P_{c}^{*}$ are dependent on the vegetation canopy and the incident PAR flux. Prior analyses (e.g., Sellers, 1987) have indicated that $g_{c}^{*}$ and $P_{c}^{*}$ should increase almost linearly with PAR and, therefore, $\partial g_{c}^{*} / \partial \mathrm{PAR}$ and $\partial P_{c}^{*} /$ OPAR might be treated as conservative surface properties. Put simply, a bare soil surface should show no change in conductance or "photosynthesis" with increasing PAR and so its associated partial derivatives of $g_{c}^{*}$ and $P_{c}^{*}$ would be zero. A thickly vegetated surface, on the other hand, would exhibit a strong sensitivity to PAR (nonzero partial derivatives of $g_{c}^{*}$ and $P_{c}^{*}$ ).

The theoretical study of Sellers (1987) proposed that for ideal conditions SR should be nearlinearly related to the derivatives of $g_{c}^{*}$ and $P_{c}^{*}$ with respect to PAR:

$$
\mathrm{SR} \propto \frac{\partial g_{c}^{*}}{\partial \mathrm{PAR}}, \frac{\partial P_{c}^{*}}{\partial \mathrm{PAR}} .
$$

The relationship described above should hold where a) the canopy consists of spatially uniform cover of green leaves, b) the reflectance of the background and understory in the chlorophyll absorption band is approximately equal to that of the overlying vegetation, and c) the wavebands of the sensing instrument are configured so that the perceived scattering coefficients of the leaves conform to

$$
\omega_{N}=1-\left[\frac{G(\mu)}{2 \mu}\right]^{2}\left(1-\omega_{\pi}\right),
$$

where $\omega_{N}$ and $\omega_{\pi}$ are the leaf scattering coeffi- cients in the near infrared and PAR wavelength intervals, respectively, $G(\mu)$ is the relative projected area of leaf elements in the direction of $\cos ^{-1} \mu$, and $\mu$ is the cosine of the zenith angle of the incident radiation flux (see Sellers, 1987).

During 1987, the First ISLSCP Field Experiment (FIFE) was conducted in a $15 \mathrm{~km} \times 15 \mathrm{~km}$ area near Manhattan, Kansas. In this article, we report on an analysis of the surface flux and surface reflectance measurements made at a site in the FIFE study area. The fluxes of water vapor and carbon dioxide were measured using the micrometeorological eddy correlation technique (see, e.g., Kaimal, 1975; Kanemasu et al., 1979; Verma, 1990), and the reflectance measurements were made with a helicopter-mounted Barnes Modular Multiband Radiometer (MMR). The effective narrow-band visible and near-infrared scattering coefficients for Landsat TM Bands 3 and 4, which correspond to the bands on the helicopter MMR, were calculated to be $0.12-0.18$ and 0.95-0.97, respectively, for individual grass leaves from the data of Walter-Shea (personal communication) collected during FIFE. For calculations involving the penetration of broad-band PAR (0.4-0.7 $\mu \mathrm{m})$ into the canopy we have assumed ${ }^{1} \omega_{\pi}=0.2$, following the calculation of Sellers (1987). Equation (6) is, therefore, approximately satisfied for a spherical leaf angle distribution $[\mathrm{G}(\mu)=0.5]$, and so we might expect that the relationship (5) should hold reasonably well for the prairie site being studied here. The purpose of this article is to test the hyothesis represented in this relationship with the field measurements collected in this study. The data presented here are representative of canopy scale and, therefore, can be considered as a test case for investigating the use of the relationship (5) for remote sensing applications.

\section{MATERIALS AND METHODS}

\section{Site}

The study was conducted in 1987 at a tallgrass prairie site $\left(39^{\circ} 03^{\prime} \mathrm{N}, 96^{\circ} 32^{\prime} \mathrm{W}, 445 \mathrm{~m}\right.$ above

${ }^{1}$ Values of $\omega_{\pi}$ derived from the observations of $\mathbf{E}$. A. WalterShea (University of Nebraska-Lincoln, personal communication) vary from 0.17 to 0.19 . 
m.s.l.,' FIFE site \#16) near Manhattan, Kansas. The soil is predominantly Dwight silty clay loam (Typic Natrustolls). The vegetation is dominated by three $\mathrm{C}_{4}$ grass species: big bluestem (Andropogon gerardii), indiangrass (Sorghastrum nutans), and switchgrass (Panicum virgatum). The prairie was burned in the spring of 1987 . The experimental area had been lightly grazed for several years, but was not grazed in 1986 and 1987.

\section{Micrometeorological Measurements}

Fluxes of carbon dioxide, water vapor, sensible heat, and momentum were measured with eddy correlation sensors mounted $2.25 \mathrm{~m}$ above the ground. The sensors included: a three-dimensional sonic anemometer (Kaijo Denki Co., Tokyo, Japan, Model DAT-310), one-dimensional sonic anemometers (Kaijo Denki Co., Tokyo, Japan, Model DAT-110; Campbell Scientific, Logan, Utah, Model CA27), fine wire $(0.025 \mathrm{~mm})$ thermocouplès (Campbell Scientific, Model 127), a Lyman-alpha hygrometer (A.I.R., Inc., Boulder, CO, Model LA-1) with a $5 \mathrm{~mm}$ path length, and a rapid response $\mathrm{CO}_{2}$ sensor with a $200 \mathrm{~mm}$ path length (Bingham et al., 1978; Anderson et al., 1984). Net radiation, PAR, soil heat flux, air temperature, and humidity were also measured. Details on the instrumentation and procedure can be found in Kim and Verma (1990a,b). The configuration of the flux instrumentation indicates that an area extending $100 \mathrm{~m}$ or so upwind of the instrumentation would have the strongest $(\sim 70 \%)$ influence on the measured flux (see, e.g., Schuepp et al., 1990).

\section{Plant and Soil Measurements}

The surface soil water content $(0-0.1 \mathrm{~m})$ was monitored gravimetrically almost every day, and the subsurface water content (0.1-1.4 m) was measured with a neutron probe on a weekly basis. Leaf area index was measured approximately every 2 weeks.

\section{Reflectance Measurements}

Measurements of surface reflectance were made with a helicopter-mounted MMR from $230 \mathrm{~m}$ above the ground. The MMR has eight spectral channels; however, only two channels were used in the analysis: $0.63-0.68 \mu \mathrm{m}$ (MMR3 or visiblered) and 0.75-0.88 $\mu \mathrm{m}$ (MMR4 or near infrared). A second MMR was positioned on the surface to measure reflected radiance from a barium sulfate reference panel to obtain a value for irradiance. These reference panel measurements were made at 1-min intervals starting $30 \mathrm{~min}$ before the helicopter missions and ending 20-30 min after the helicopter left the FIFE study area. The reference panel was calibrated using procedures outlined in Jackson et al. (1987), and the MMR was calibrated using procedures described in Markham et al. (1988), thus allowing determination of absolute radiance from the MMR voltage responses.

A minimum of 25 and a maximum of 150 measurements were taken over the study site within $100 \mathrm{~m}$ of the flux station during each mission. Two to $5 \mathrm{~min}$ were required to obtain these measurements. Data were collected under clear sky conditions one or two times a day. The sampled areas within the site were usually concentrated upwind of the micrometeorological flux sensors. The vegetation across the site was fairly uniform, with little variation in topography.

The raw digital count values from the MMR were converted to sensor radiances using the calibration data taken prior to the experiment. The sensor radiances were then corrected for atmospheric effects using an algorithm developed for FIFE by Fraser et al. (1989) based on the Dave (1978) algorithm that includes the effects of multiple scattering in the atmosphere and between the atmosphere and the surface. Aerosol optical depths were determined from a suntracking photometer, operating in discrete bands in the 380=1020 $\mathrm{nm}$ region (Wrigley et al., 1990; Halthore et al., 1990) during the helicopter data acquisition. Gaseous absorption terms $\left(\mathrm{CO}_{2}, \mathrm{O}_{3}\right.$, $\mathrm{H}_{2} \mathrm{O}$, etc.) were calculated using Lowtran-7 (Kniezys, 1988) from concurrent measurements of radiosonde atmospheric water-vapor profiles. The SR was then calculated for the site using the average site reflectance in MMR3 and MMR4.

\section{Estimating Canopy Conductance}

Canopy stomatal conductance $\left(g_{c}\right)$ can be estimated from the surface conductance, $g_{c}(\mathrm{PM})$ (canopy conductance and surface conductance are roughly equivalent as the soil evaporation tends 


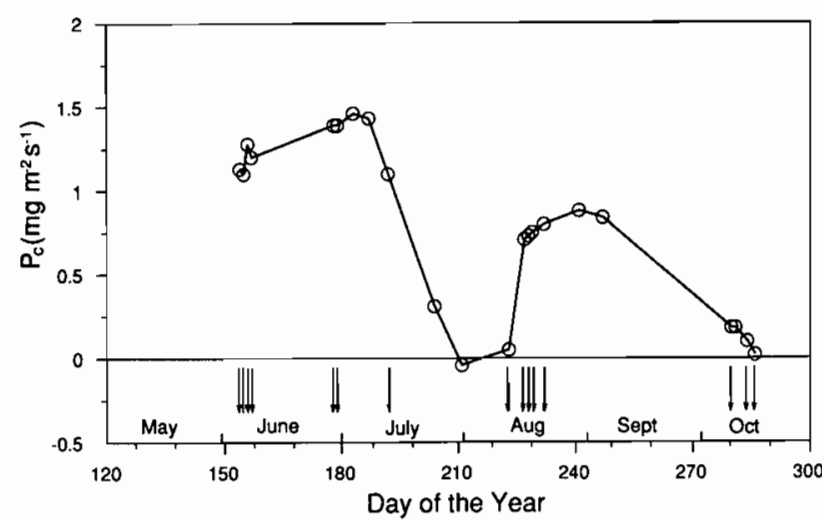

Figure 3. Seasonal variation in midday $(1230-1430 \mathrm{~h}$, Central Daylight Savings Time) values of canopy photosynthesis (after Verma et al., 1992). The days on which SR was measured are indicated with arrows.

increased to about $0.75 \mathrm{mg} \mathrm{m}^{-2} \mathrm{~s}^{-1}$. The photosynthetic rates diminished rapidly as the vegetation senesced. The midday value of $P_{c}$ in early to mid-October was about $0.1 \mathrm{mg} \mathrm{m}^{-2} \mathrm{~s}^{-1}$.

The days on which SR was measured are indicated in Figures 2 and 3. The seasonal progression of SR for the study site is shown in Figure 4. Values of SR were high, ranging from 8.9 to 10.5 , in June-early July when the plants were growing vigorously. During the early senescence stage which followed the dry period in late Julyearly August (see Fig. 1), the SR values reduced to about 5.4. The lowest values $(\approx 2.2)$ of SR were observed during mid-October toward the end of the senescence period.

\section{Simple Ratio Vegetation Index, Related to Unstressed Canopy Conductance and Unstressed Canopy Photosynthesis}

The procedure described in Appendix A was employed to define the form and coefficients for the stress factors, $f(x)$ and $h(x)$, used in Eqs. (3) and (4). Measured values of $T, D$, and $\theta_{s}$ were used to calculate these stress factors. The values of $g_{c}$ and $P_{c}$ were then divided by the stress factors to estimate $g_{c}^{*}$ and $P_{c}^{*}$ [see Eqs. (3) and (4)]. Plots of $g_{c}^{*}$ and $P_{c}^{*}$ against PAR are shown in Figures 5 and 6. Estimates of $\partial g_{c}^{*} / \partial$ PAR and $\partial P_{c}^{*} / \partial$ PAR were obtained by applying simple linear fits to these data (only afternoon data were used in estimating $\partial g_{c}^{*} / \partial$ PAR to minimize confounding effects of rapid time rate of change in soil and dew evaporation). The values of $\partial g_{c}^{*} / \partial$ PAR and

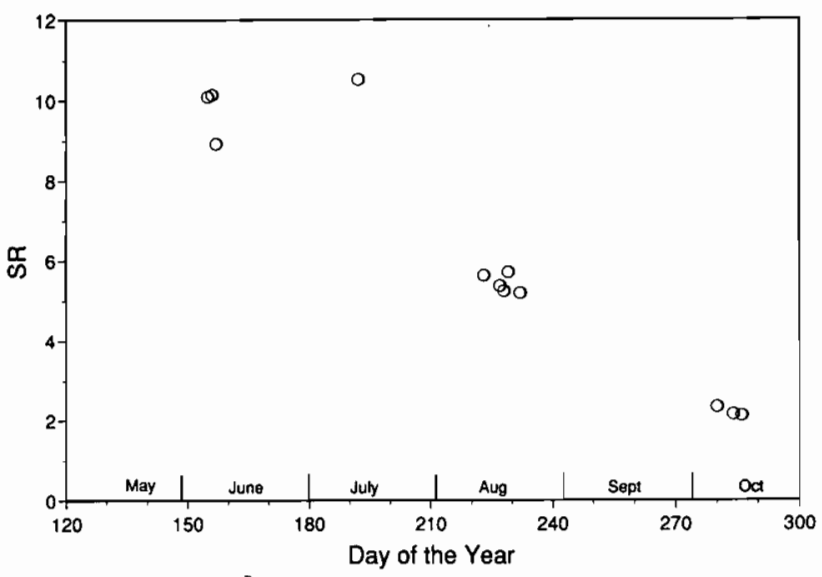

Figure 4. Seasonal variation in the simple ratio vegetation index (SR).

$\partial P_{c}^{*}$ / $\partial$ PAR are shown in Table 1 . The coefficient $\left(r^{2}\right)$ of determination was generally high, except on 4 June, 11 August, and 8 October. Because of rain on 2 and 3 June, our analysis of data on 4 June is subject to problems arising from a rapid rate of change in soil evaporation. During JuneAugust when $g_{c}^{*}$ and $P_{c}^{*}$ were computed, $11 \mathrm{Au}$ gust was a day with the driest soil moisture conditions of all the days. Our empirical approach to calculate the stress factors under such severe moisture stress conditions is probably not adequate (e.g., see Kim and Verma, 1991). The value of $r^{2}$ on 8 October is low because the canopy conductance and photosynthetic rates diminished rapidly as vegetation senesced in October.

On two days (7 and 13 October), the canopy photosynthesis and conductance measurements were not available. The values of $\partial g_{c}^{*} / \partial$ PAR and $\partial P_{c}^{*} / \partial \mathrm{PAR}$ were assumed ${ }^{4}$ to be the same as those on 8 October (no reflectance measurements were available on 8 October). Also, note that the canopy light response function used in the analysis to obtain the stress factors is not exactly consistent with the simple linear model used to relate $g_{c}^{*}$ and $P_{c}^{*}$ to PAR. However, this simplification is unlikely to lead to serious errors (see Figs. 5 and 6$)$.

\footnotetext{
${ }^{4}$ In October when soil moisture conditions were similar, the day-to-day changes in $\partial g_{c}^{*} / \partial$ PAR and $\partial P_{c}^{*} / \partial$ PAR were negligible because of the senescing prairie vegetation and low values of $L_{T}$. As indicated in Table 2, soil moisture during 7-13 October was quite similar, and, therefore, this interpolation is justified.
} 

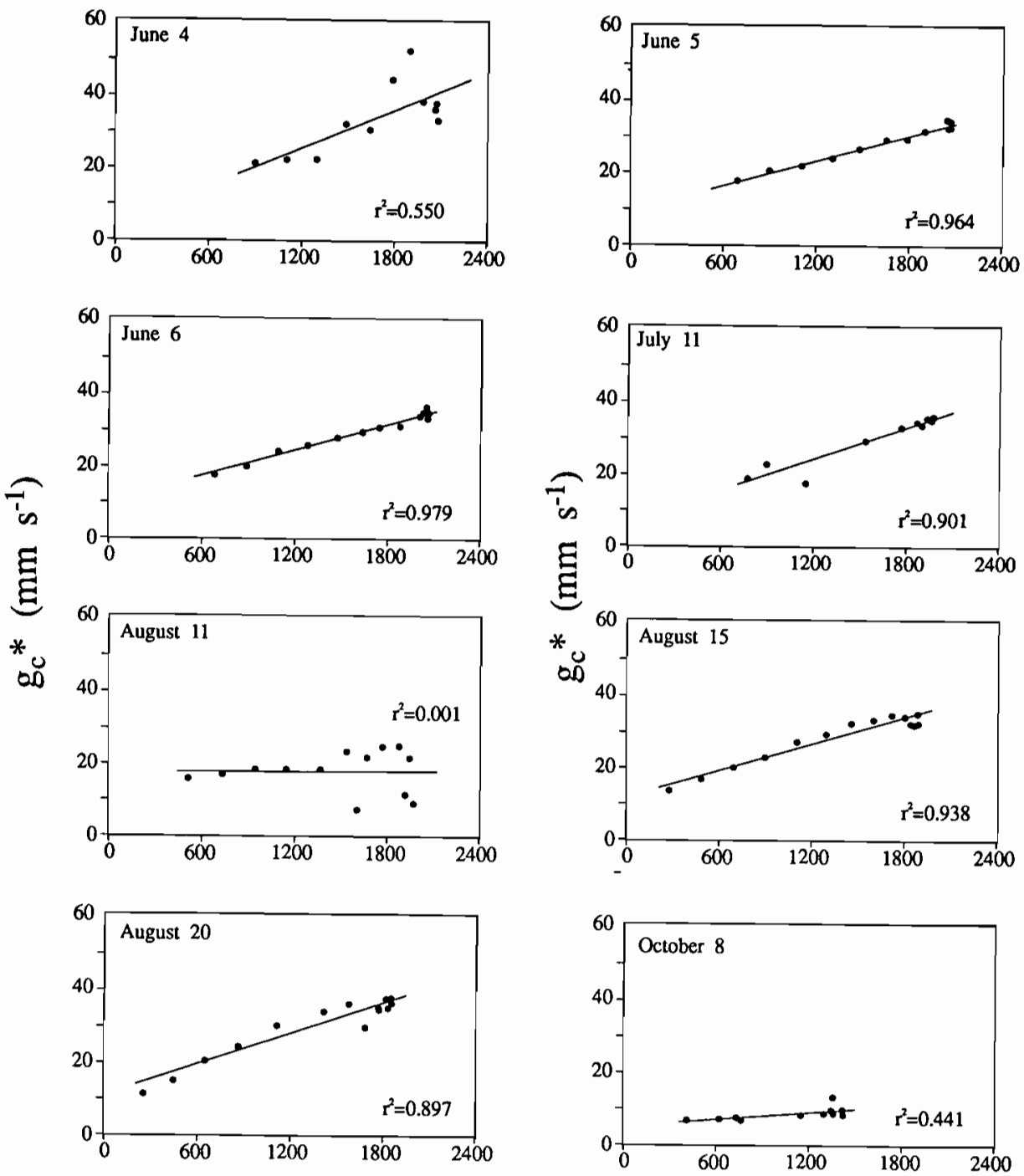

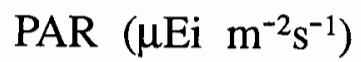

Figure 5. Unstressed canopy conductance $\left(g_{c}^{*}\right)$ as a function of the photosynthetically active radiation (PAR). Only afternoon data were used to minimize confounding effects. Estimates of $\partial g_{c}^{*} / \partial$ PAR were obtained by applying simple linear fits to these data.

In Figures 7 and 8, SR is plotted against $\partial g_{c}^{*} /$ $\partial$ PAR and $\partial P_{c}^{*} /$ PPAR, respectively. As indicated above, the data included in these two figures are from a range of soil moisture and meteorological conditions and cover different stages in the annual life cycle of the prairie vegetation (Table 1 ). The data from 4 June-11 July are from a period when the soil water was not limiting and the plants were growing vigorously. The data point from 11 August is during the dry period, when severe moisture stress conditions prevailed. With about $67 \mathrm{~mm}$ of rainfall on 13 August, the soil water content increased significantly. The data collected during 15-20 August reflect this change in soil water conditions. The data during 7-13 October are from the senescence period. It can be noted that the SR and green $L_{T}$ values (Figs. 1 and 4) do not seem to track each other well. One reason ${ }^{5}$ may be that the canopy was much less lush in August than in June-July. This would explain the

${ }^{5}$ To estimate $L_{T}$, leaves of eight $0.18 \mathrm{~m}^{2}$ area were harvested. The harvested foliage was divided into live and dead components, and then fed through an area meter. However, this procedure took no account of changes in the greenness / lushness of live vegetation, and in August the leaves were less green than in June-July. 

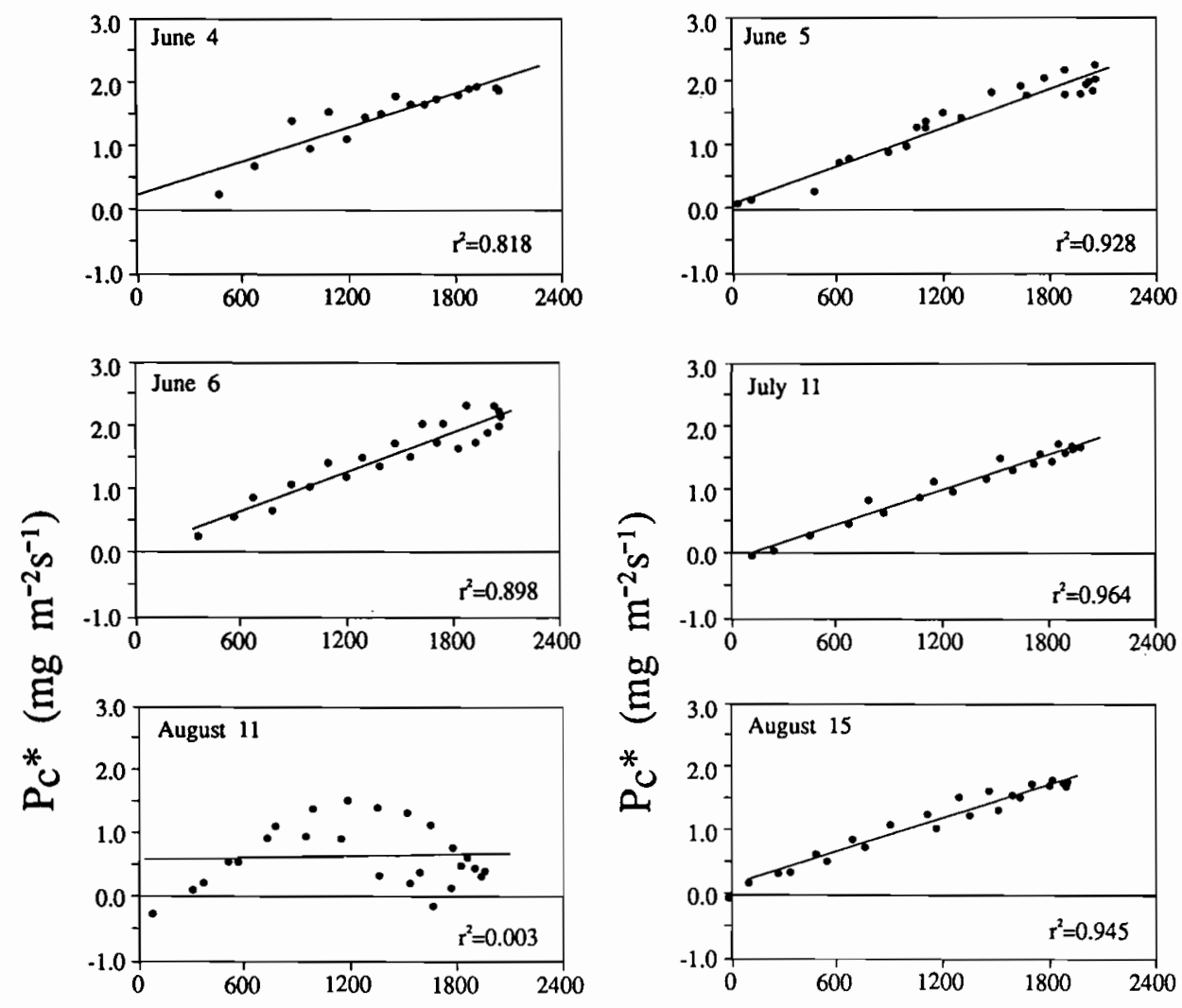

OD
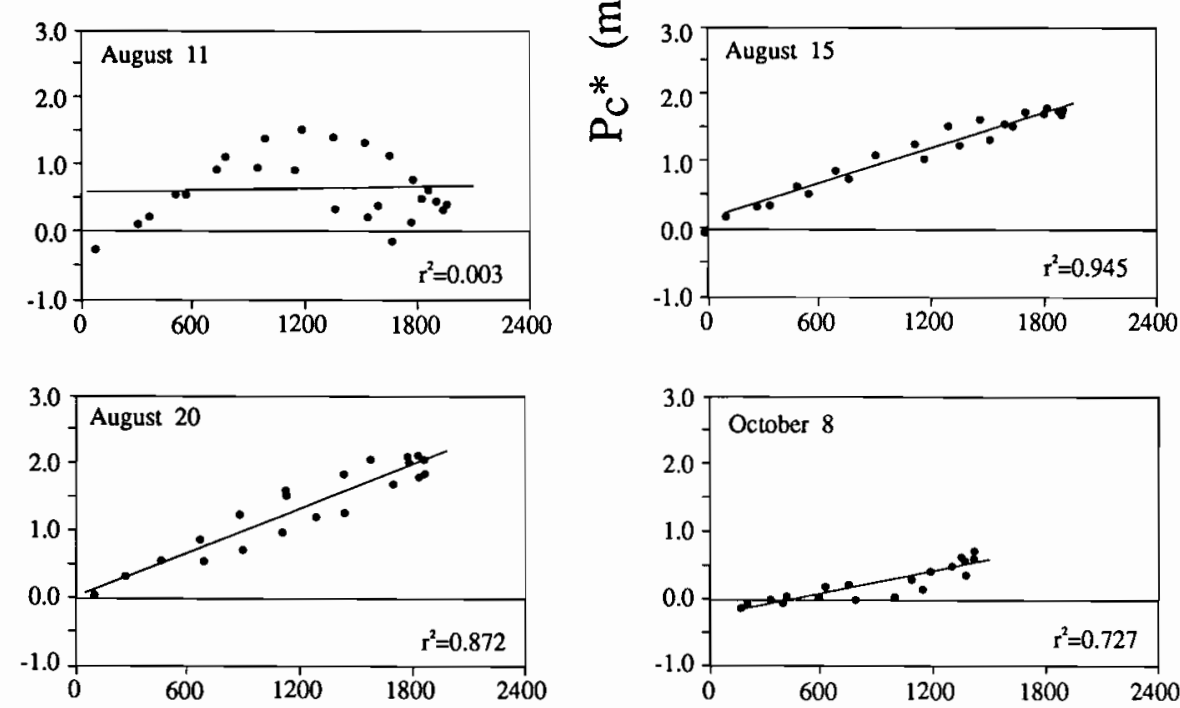

\section{PAR $\left(\mu E i \mathrm{~m}^{-2} \mathrm{~s}^{-1}\right)$}

Figure 6. Unstressed canopy photosynthesis $\left(P_{c}^{*}\right)$ as a function of the photosynthetically active radiation (PAR). Estimates of $\partial P_{c}^{*} / \partial$ PAR were obtained by applying simple linear fits to the data.

Table 1. Values of $\partial g_{c}^{*} / \partial$ PAR and $\partial P_{c}^{*} / \partial$ PAR

\begin{tabular}{lccccc}
\hline & $g_{c}^{*} v s . P A R$ & & \multicolumn{2}{c}{$P_{c}^{*}$ vs. PAR } \\
\cline { 2 - 3 } \cline { 5 - 6 } Date $(1987)$ & $\left(\partial g_{c}^{*} / \partial P A R\right) \times 1000$ & & & $\left(\partial P_{c}^{*} / \partial P A R\right) \times 1000$ & \\
$\left(m m^{-1} / \mu E i m^{-2} s^{-1}\right)$ & $r^{2}$ & & $\left.s^{-1} / \mu E i m^{-2} s^{-1}\right)$ & $r^{2}$ \\
\hline 4 June & 16.75 & 0.550 & 0.86 & 0.818 \\
5 June & 11.29 & 0.964 & 0.98 & 0.928 \\
6 June & 11.15 & 0.979 & 1.02 & 0.898 \\
11 July & 14.06 & 0.901 & 0.89 & 0.964 \\
11 August & 0.05 & 0.001 & 0.05 & 0.003 \\
15 August & 11.66 & 0.938 & 0.85 & 0.945 \\
20 August & 13.16 & 0.897 & & 1.04 & 0.872 \\
7 October & 3.13 & - & 0.51 & - \\
8 October & 3.13 & 0.441 & 0.51 & 0.727 \\
13 October & 3.13 & - & 0.51 & - \\
\hline
\end{tabular}

${ }^{a}$ Estimated data (see text for details). 
Table 2. Information of Annual Life Cycle Stage, Green Leaf Area Index $\left(\mathrm{L}_{\tau}\right)$, Extractable Soil Water $\left(\theta_{s}=0-1.4 \mathrm{~m}\right.$ depth), Midday (averaged during 1230-1430 h, Central Daylight Savings Time), Mean Air Temperature $(T)$, and Vapor Pressure Deficit $(D)$ and Photosynthetically Active Radiation (PAR) on Selected Days When Reflectance and Flux Measurements Were Available ${ }^{a}$

\begin{tabular}{lclccccc}
\hline \multicolumn{1}{c}{ Date } & $\begin{array}{c}\text { Day } \\
\text { Number }\end{array}$ & $\begin{array}{c}\text { Annual Life } \\
\text { Cycle Stage }\end{array}$ & $\begin{array}{c}\theta_{s} \\
(\%)\end{array}$ & $\begin{array}{c}\text { Green } \\
L_{\tau}\end{array}$ & $\begin{array}{c}T \\
\left({ }^{\circ} \mathrm{C}\right)\end{array}$ & $\begin{array}{c}D \\
(\mathrm{kPa})\end{array}$ & $\begin{array}{c}\text { PAR } \\
\left(\mu E i \mathrm{~m}^{-2} \mathrm{~s}^{-1}\right)\end{array}$ \\
\hline 4 June & 155 & Early growth & 79.3 & 1.86 & 25.4 & 1.88 & 2052 \\
5 June & 156 & Early growth & 77.7 & 1.90 & 27.1 & 1.91 & 2048 \\
6 June & 157 & Early growth & 76.2 & 1.94 & 27.8 & 2.11 & 2050 \\
11 July & 192 & Peak growth & 68.4 & 2.79 & 31.0 & 1.85 & 1971 \\
11 August & 223 & Early senescence & 24.8 & 2.44 & 32.6 & 2.87 & 1844 \\
15 August & 227 & Early senescence & 54.4 & 2.39 & 33.7 & 2.35 & 1888 \\
20 August & 232 & Early senescence & 53.4 & 2.28 & 32.8 & 2.35 & 1860 \\
7 October & 280 & Senescence & 30.7 & 0.30 & 15.5 & 1.13 & 1500 \\
8 October & 281 & Senescence & 30.4 & 0.28 & 19.8 & 1.71 & 1351 \\
13 October & 286 & Senescence & 32.5 & $<0.20$ & 22.7 & 2.13 & 1165 \\
\hline
\end{tabular}

${ }^{a} T$ and $D$ were measured at $2.25 \mathrm{~m}$ above ground.

lower SR values in August compared to those in early June (in spite of larger values of green $L_{r}$ in August) and also the lower values of $\partial g_{c}^{*} / \partial$ PAR and $\partial P_{c}^{*} / \partial \mathrm{PAR}$.

A linear regresson of all of the SR- $\partial P_{c}^{*} \mid$ DPAR data yielded a $r^{2}$ of 0.28 (Fig. 8). Similarly, a linear regression of all the data in the SR$\partial g_{c}^{*} / \partial$ PAR relationship (Fig. 7) resulted in $r^{2}=0.52$. It is safe to assume that the representation of the effect of moisture stress on $g_{c}^{*}$ and $P_{c}^{*}$ used here is inadequate on 11 August when extremely dry soil moisture conditions prevailed. Also, as mentioned above, the value of $\partial g_{c}^{*} /$ IPAR on 4 June was probably affected by problems associated with a rapid change in soil evaporation. Excluding the data points on 4 June and 11 August, a linear regression of the SR- $\partial g_{c}^{*} /$ כPAR data (solid line shown in Fig. 7) resulted ${ }^{6}$ in $r^{2}=0.62$. Similarly, excluding the data point on 11 August, a linear regression of the SR- $\partial P_{c}^{*}$ I OPAR data (solid line shown in Fig. 8) yielded ${ }^{6}$ $r^{2}=0.53$.

Even though there is some scatter in the data, Figures 7 and 8 seem to support the hypothesis suggested by Sellers (1987) that there should be near-linear relationships between the simple ratio vegetation index (SR) and the response of the unstressed canopy conductance and the photosynthetic capacity to the incident PAR. The data scatter in Figures 7 and 8 could have resulted

${ }^{6}$ The coefficient $\left(r^{2}\right)$ of determination was statistically significant at the 0.05 level. from several simplifying assumptions used in the analysis presented above. First, there was no allowance for soil evaporation in the calculation of $g_{c}(\mathrm{PM})$; it was assumed that all of the latent heat flux was due to canopy transpiration. Second, the soil respiration was not measured directly, but was estimated using empirical relationships to describe plant respiration. Third, the expressions used to calculate the environmental stress factors are empirical and need further evaluation.

The scatter in Figures 7 and 8 is consistent with expectations given the experimental method-

Figure 7. Simple ratio vegetative index (SR) as a function of the derivative ( $\left.\partial g_{c}^{*} / \partial \mathrm{PAR}\right)$ of the unstressed canopy conductance with respect to the photosynthetically active radiation (PAR). The coefficient $\left(r^{2}\right)$ of determination for the linear regression is 0.52 for all data and 0.62 for the data set excluding 4 June and 11 August. The solid line represents the linear regression of the data set excluding 4 June and 11 August.

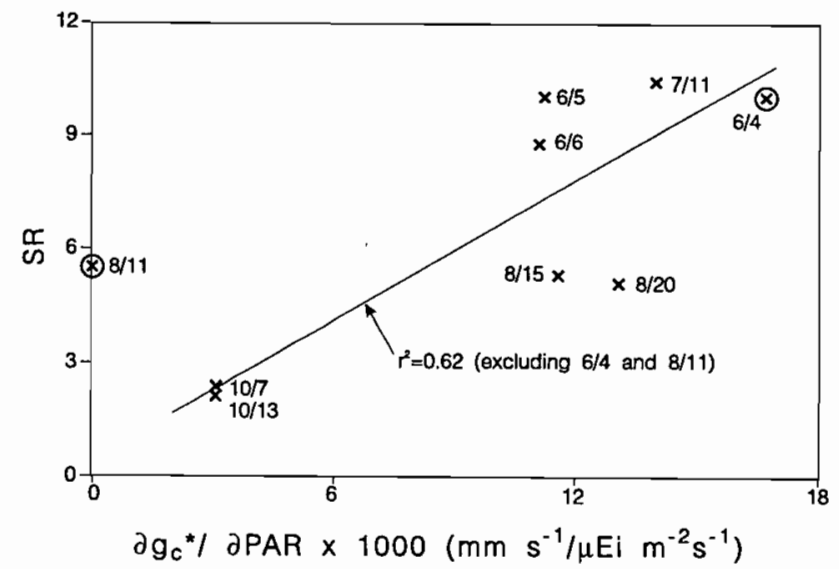




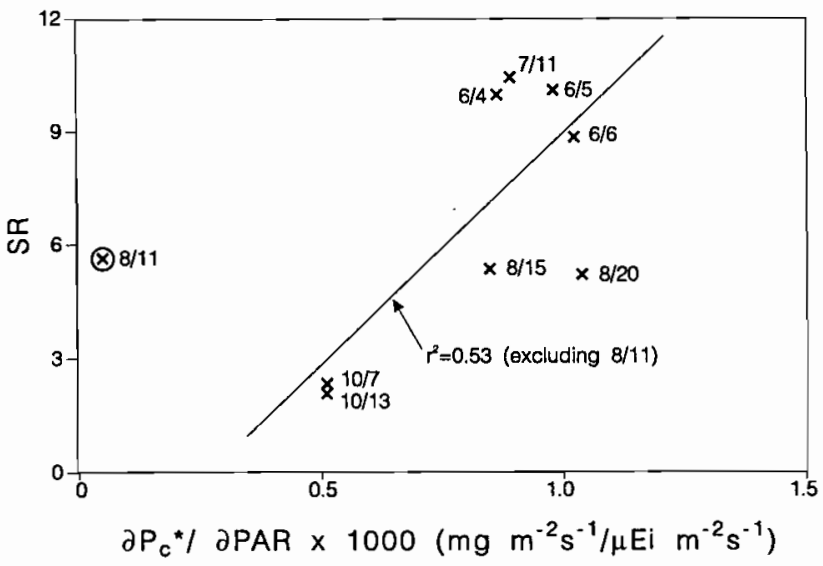

Figure 8. Simple ratio vegetative index (SR) as a function of the derivative ( $\partial P_{c}^{*} / \partial \mathrm{PAR}$ ) of the unstressed canopy photosynthesis with respect to the photosynthetically active radiation (PAR). The coefficient $\left(r^{2}\right)$ of determination for the linear regression is 0.28 for all data and 0.53 for the data set excluding 11 August. The solid line represents the linear regression of the data set excluding 11 August.

ologies and simple analytical tools we have applied. Further work is needed to address the problems outlined above to bring us closer to the goal of using satellite data to provide information on energy and mass exchanges in various terrestrial ecosystems.

\section{SUMMARY AND CONCLUDING REMARKS}

The surface fluxes of carbon dioxide and water vapor were measured employing the micrometeorological eddy correlation technique during FIFE in 1987. Concurrent measurements were also made of reflectance using a helicopter-mounted Barnes MMR, from which the simple ratio vegetation index (SR) was calculated. Both of these data sets provide information on the grassland canopy at a comparable scale $(10-100 \mathrm{~m})^{2}$.

Using our data on water vapor and carbon dioxide fluxes, empirical relationships for the environmental stress factors were developed to account for the effect of temperature, ambient vapor pressure deficit, and extractable soil water. These factors were then used in conjunction with the measured surface fluxes to compute unstressed canopy conductance $\left(g_{c}^{*}\right)$ and unstressed canopy photosynthesis $\left(P_{c}^{*}\right)$.

The derivatives $\left(\partial g_{c}^{*} / \partial\right.$ PAR and $\partial P_{c}^{*} / \partial$ PAR) of unstressed canopy conductance and unstressed canopy photosynthesis are dependent on the amount and type of green vegetation and, there- fore, should be amenable to remote sensing. The analysis of Sellers (1987) indicated that $\partial g_{c}^{*} /$ $\partial P A R$ and $\partial P_{c}^{*} / \partial P A R$ should be near-linearly related to SR, and the first-order, preliminary analysis of our data seems to support this hypothesis. However, before such relationships can be employed in satellite remote sensing applications, more work is needed. Future studies should include: a) adequate allowance of soil evaporation in calculating canopy conductance, b) direct measurement of soil respiration, c) further development and evaluation of environmental stress factors, and d) more frequent measurements of canopy reflectance under similar illumination conditions.

\section{APPENDIX A}

The procedure employed to derive the stress factors $f(x)$ and $h(x)$ [see Eqs. (3) and (4)] is described here.

Leaf stomatal conductance $\left(g_{l}\right)$ can be described in terms of a simple multiplicative model (see, e.g., Jarvis, 1976; Kim and Verma, 1991):

$$
g_{l}=g^{*}(\mathrm{PAR}) \cdot\left[f(T) \cdot f(D) \cdot f\left(\theta_{s}\right)\right]
$$

where $g^{*}(\mathrm{PAR})$ is the unstressed value of leaf stomatal conductance. Similarly, leaf photosynthesis can be estimated as

$$
P_{l}=P^{*}(\mathrm{PAR}) \cdot\left[h(T) \cdot h(D) \cdot h\left(\theta_{s}\right)\right],
$$

where $P_{l}^{*}(\mathrm{PAR})$ is the unstressed value of leaf photosynthesis. The stress factors $f(x)$ and $h(x)$ account for the effect of temperature $\left(T\right.$ in $\left.{ }^{\circ} \mathrm{C}\right)$, ambient vapor pressure deficit $(D$ in $\mathrm{kPa})$, and extractable soil water $\left(\theta_{s}\right.$ in $\left.\%\right)$. Values of $\theta_{s}$ were computed as the ratio of actual to total soil moisture held with a water potential between $-1 / 30$ and $-1.5 \mathrm{MPa}$.

Equations (A-1) and (A-2) can be integrated ("scaled up") to provide estimates of canopy stomatal conductance $\left(g_{c}\right)$ and canopy photosynthesis $\left(P_{c}\right)$ :

$$
g_{c}=F(\Sigma) \int_{0}^{L_{T}} g^{*}(\mathrm{PAR}) d L_{T}=g_{c}^{*}(\mathrm{PAR}) \cdot F(\Sigma),
$$

and

$$
P_{c}=H(\Sigma) \int_{0}^{L_{T}} P_{l}^{*}(\mathrm{PAR}) d L_{T}=P_{c}^{*}(\mathrm{PAR}) \cdot H(\Sigma),
$$


where $F(\Sigma)=f(T) \cdot f(D) \cdot f\left(\theta_{s}\right), H(\Sigma)=h(T) \cdot h(D) \cdot h\left(\theta_{s}\right)$, and $L_{T}=$ total green leaf area index. We $e_{i}$ assume that the stress factors are independent of leaf area index.

The response of the unstressed leaf stomatal conductance and leaf photosynthesis to PAR was estimated using a hyperbolic relationship (e.g., Monteith, 1965b):

$$
\begin{aligned}
& g_{l}^{*}(\mathrm{PAR})=\left(\begin{array}{ll}
a_{1} & \mathrm{PAR} \downarrow
\end{array}\right) /\left(a_{2}+\mathrm{PAR} \downarrow\right), \\
& P_{l}^{*}(\mathrm{PAR})=\left(\begin{array}{ll}
a_{1}^{\prime} & \mathrm{PAR} \downarrow
\end{array}\right) /\left(a_{2}^{\prime}+\mathrm{PAR} \downarrow\right),
\end{aligned}
$$

where PAR $\downarrow$ is the normal (relative to the leaf) flux density of incident PAR and $a_{1}, a_{2}, a_{1}^{\prime}$, and $a_{2}^{\prime}$ are empirically derived constants. ${ }^{7}$

Using Eqs. (A-5) and (A-6), Eqs. (A-3) and (A-4) can be rewritten as

$$
\begin{aligned}
g_{c}= & {\left[\int_{0}^{L_{T}}\left(\frac{\overline{a_{1}} \text { PAR } \downarrow}{\overline{a_{2}}+\text { PAR } \downarrow}\right) d L_{T}\right] } \\
& \times f(T) f(D) f\left(\theta_{s}\right)
\end{aligned}
$$

and

$$
\begin{aligned}
P_{c}= & {\left[\int_{0}^{L_{T}}\left(\overline{\overline{a_{1}^{\prime}} \text { PAR } \downarrow}\right) d L_{T}\right] } \\
& \times h(T) h(D) h\left(\theta_{s}\right) .
\end{aligned}
$$

Substituting the Ross-Goudriaan function (see, e.g., Sellers, 1985, Table 3, p. 1351), Eqs. (A-7) and (A-8) can be simplified to

$$
\begin{aligned}
g_{c}= & \frac{\overline{a_{1}}}{k_{\pi}}\left[\ln \frac{\mu \overline{a_{2}}+G(\mu) \mathrm{PAR}_{0}}{\mu \overline{a_{2}}+G(\mu) \mathrm{PAR}_{0} e^{-k_{\pi_{T} L_{T}}}}\right] \\
& \times f(T) f(D) f\left(\theta_{s}\right), \\
P_{c}= & \overline{a_{1}^{\prime}} \\
k_{\pi} & \left.\ln \frac{\mu \overline{a_{2}^{\prime}}+G(\mu) \mathrm{PAR}_{0}}{\mu \overline{a_{2}^{\prime}}+G(\mu) \mathrm{PAR}_{0} e^{-k_{\pi} L_{T}}}\right] \\
& \times h(T) h(D) h\left(\theta_{s}\right),
\end{aligned}
$$

where $k_{\pi}=$ extinction coefficient for $\mathrm{PAR}=$ $\left(1-\omega_{\pi}\right)^{1 / 2} G(\mu) / \mu, \omega_{\pi} \sim 0.2, G(\mu) \sim 0.5$ (for spherical leaf distribution), and $\mathrm{PAR}_{0}=\mathrm{PAR}$ flux above the canopy. (Note that for nonsaturating values of $\mathrm{PAR}_{0}, \mathrm{~g}_{c}^{*}$ and $P_{c}^{*}$ are near-linear functions of PAR ${ }_{0}$; i.e., $\partial g_{c}^{*} / \partial$ PAR and $\partial P_{c}^{*} / \partial$ PAR are almost constant. This seems to be a reasonable approximation to make given the results shown in Fig. 5.)

${ }^{7}$ The parameters, $a_{1 \text { and }} a_{1}^{\prime}$, represent the asymptotic values of $g_{l}^{*}$ and $P_{l}^{*}$ when PAR $\rightarrow \infty$, and can be considered as the maximum stomatal conductance and the maximum leaf photosynthesis, respectively (under optimal conditions). The terms $a_{2}$ and $a_{2}^{\prime}$ define the curvature of the responses to PAR.
The response of canopy conductance and canopy photosynthesis to temperature $(T)$ was estimated using the following relationship (e.g., Jarvis, 1976):

$$
f(T)=\frac{\left(T-T_{\min }\right)\left(T_{\max }-T\right)^{b}}{\left(a_{3}-T_{\min }\right)\left(T_{\max }-a_{3}\right)^{b}}
$$

and

$$
h(T)=\frac{\left(T-T_{\min }\right)\left(T_{\max }-T\right)^{b^{\prime}}}{\left(a_{3}^{\prime}-T_{\min }\right)\left(T_{\max }-a_{3}^{\prime}\right)^{b^{\prime}}}
$$

where

$$
b=\left(T_{\max }-a_{3}\right) /\left(a_{3}-T_{\min }\right)
$$

and

$$
b^{\prime}=\left(T_{\max }-a_{3}^{\prime}\right) /\left(a_{3}^{\prime}-T_{\min }\right) .
$$

The minimum $\left(T_{\min }\right)$ and the maximum $\left(T_{\max }\right)$ temperatures for both canopy conductance and canopy photosynthesis were assumed to be $0^{\circ} \mathrm{C}$ and $55^{\circ} \mathrm{C}$, respectively (Knapp, 1985). The terms $a_{3}$ and $a_{3}^{\prime}$ can be considered as optimum temperatures for canopy conductance and canopy photosynthesis.

A curvilinear reduction in canopy conductance and canopy photosynthesis with increasing vapor pressure deficit $(D)$ was assumed (e.g., Lohammar et al., 1980):

$$
\begin{aligned}
& f(D)=1 /\left(1+a_{4} D\right), \\
& h(D)=1 /\left(1+a_{4}^{\prime} D\right),
\end{aligned}
$$

where $a_{4}$ and $a_{4}^{\prime}$ are constants. The response to extractable soil water $\left(\theta_{s}\right)$ was estimated using a negative exponential relationship (e.g., Stewart, 1988; Kim and Verma, 1991):

$$
\begin{aligned}
& f\left(\theta_{s}\right)=1-\exp \left(-a_{5} \theta_{s}\right), \\
& h\left(\theta_{s}\right)=1-\exp \left(-a_{5}^{\prime} \theta_{s}\right),
\end{aligned}
$$

where $a_{5}$ and $a_{5}^{\prime}$ are constants.

As discussed in the subsection Estimating Canopy Conductance, $g_{c}$ was computed from our half-hourly measurements of fluxes of net radiation, soil heat, sensible heat, and latent heat. Values of $\mu$ and $k_{\pi}$ were calculated every $0.5 \mathrm{~h}$. The stress functions were then evaluated by fitting (nonlinear least squares) data $\left(g_{c}, \mu, k_{\pi}, \mathrm{PAR}_{0}, T\right.$, $\left.D, \theta_{s}, L_{T}\right)$ to Eq. (A-9):

$$
\begin{aligned}
& a_{3}=26.5 \pm 0.5, \quad a_{4}=0.570 \pm 0.087, \\
& a_{5}=0.008 \pm 0.002 \quad\left(r^{2}=0.769\right) .
\end{aligned}
$$

Similarly, $P_{c}$ was computed as discussed in the text. Then the coefficients in the stress functions 
were evaluated by fitting data $\left(P_{c}, \mu, k_{\pi}, \mathrm{PAR}_{0}, T\right.$, $\left.D, \theta_{s}, L_{T}\right)$ to Eq. (A-10):

$$
\begin{aligned}
& a_{3}^{\prime}=28.3 \pm 2.1, \quad a_{4}^{\prime}=0.442 \pm 0.079, \\
& a_{5}^{\prime}=0.008 \pm 0.002 \quad\left(r^{2}=0.874\right) .
\end{aligned}
$$

(These values were derived from about 450 halfhour $g_{c}$ and $P_{c}$ data points collected during 20 days distributed throughout the season). It is worthwhile to note that the coefficients $\left(a_{3}, a_{3}^{\prime}\right.$, $\left.a_{4}, a_{4}^{\prime}, a_{5}, a_{5}^{\prime}\right)$ used in the stress functions operating on $g_{c}$ and $P_{c}$ are similar.

These derived stress factors were applied to the estimates of $g_{c}$ and $P_{c}$, computed from flux observations, to calculate values of $g_{c}^{*}$ and $P_{c}^{*}$ (see the third subsection under Results and Discussion). Note that while values of $L_{T}$ were used to derive the stress functions, the coefficients and the forms of stress factors are independent of the time-varying leaf area index.

\section{APPENDIX B}

Heat (or water vapor) transfer in the immediate vicinity of a vegetated surface is primarily controlled by molecular diffusion. Momentum, however, is transferred to a large extent by pressure forces, which have no analog in heat (or water vapor) transfer. Transfer of momentum in aerodynamically rough flows (e.g., over a vegetated surface) is primarily independent of molecular viscosity. Therefore, the transfer of heat (or water vapor) to or from a vegetated surface encounters greater aerodynamic resistance than does the transfer of momentum (Owen and Thomson, 1963; Chamberlain, 1966, 1968; Thom, 1972; Verma, 1989). Accordingly, an "excess resistance" term $r_{b}$ is defined:

$$
r_{a}=r_{a m}+r_{b}
$$

where $r_{a n}$ and $r_{a}$ are the aerodynamic resistance to transfer of momentum and sensible heat/water vapor, respectively.

The terms $r_{a m}$ and $r_{a}$ can be obtained from

$$
\tau=\rho \bar{U} / r_{a m}
$$

and

$$
H=\rho C_{p}\left(T_{m}-\bar{T}\right) / r_{a},
$$

where $\tau\left(=\rho u_{*}^{2}\right)$ is the momentum flux, $u_{*}$ is the friction velocity, and $\bar{U}$ and $\bar{T}$ are the mean horizontal wind speed and air temperature at a reference height. The term $T_{m}$ represents an effective surface temperature. Equation (B-2) can be rewritten as

$$
r_{a m}=\bar{U} / u_{*}^{2} .
$$

Owen and Thomson (1963) proposed a dimensionless parameter $B^{-1}$ (sublayer Stanton number) to express the difference between $r_{a}$ and $r_{a m}$ :

$$
B^{-1}=r_{a}^{+}-r_{a m}^{+},
$$

where $r_{a}^{+}$and $r_{a m}^{+}$are dimensionless resistances given by

$$
r_{a}^{+}=r_{\mathrm{a}} u_{*}
$$

and

$$
r_{a m}^{+}=r_{a m} u_{*} .
$$

Several investigations (e.g., Garratt and Hicks, 1973; Brutsaert, 1984) suggest that, for surfaces with densely spaced permeable roughness elements, as a first approximation $k B^{-1}$ can be assumed to be of the order of 2 for scalars whose Schmidt $\left(S_{c}\right)$ or Prandtl $\left(P_{r}\right)$ number is of the order of 0.6-0.8 ( $k$ is von Karman's constant). Therefore, the excess resistance term $r_{b}$ can be expressed as $r_{b} \approx\left(2 / k \mu_{*}\right)\left(S_{c} / P_{r}\right)^{2 / 3} \approx\left(2 / k \mu_{*}\right)\left(\kappa / D_{v}\right)^{2 / 3}$.

The factor $\left(S_{c} / P_{r}\right)^{2 / 3}$ is incorporated to account for the fact that the basic information was derived from heat transfer observations primarily (Wesely and Hicks, 1977). The term $\kappa$ represents the thermal diffusivity and $D_{v}$ represents the molecular diffusivity of water vapor. The effect of thermal stability was neglected in estimating $r_{b}$.

This study was supported by the National Aeronautics and Space Administration under grants NAG5-890, NCC5-26, NAG-892, and NAG-907 and by the National Science Foundation under Grant ATM-8519026. We wish to express our sincere appreciation to $\mathrm{Mr}$. Robert Clement for his valuable help in data collection and processing. Messrs. H. D. Earl and Sheldon Sharp provided valued assistance in maintenance of instruments and data acquisition systems. Mr. James Hines assisted in data computation. We extend our thanks to the entire FIFE Science Team and staff for their help and support during FIFE. Particular thanks go to the NASA helicopter crew (Willie Dykes, Charles Smith, Ed Bohl, Richard Liddle, Wayne Delaney, Richard Huey, and Dave Pierce) for the extended MMR data collection effort. We thank Mrs. Sharon Kelly and Mrs. Jan Schinstock for the stenographic work and Drs. Blaine Blad, Sam Goward, John Norman, and Elizabeth Walter-Shea for their review of this article.

\section{REFERENCES}

Anderson, D. E., Verma, S. B., and Rosenberg, N. J. (1984), Eddy correlation measurements of $\mathrm{CO}_{2}$, latent heat and 
sensible heat fluxes over a crop surface, Boundary-Layer Meteorol. 29:263-272.

Asrar, G., Fuchs, M., Kanemasu, E. T., and Hatfield, J. L. (1984), Estimating absorbed photosynthetic radiation and leaf area index from spectral reflectance in wheat, Agron. J. 76:300-306.

Baldocchi, D. D., Luxmoore, R. J., and Hatfield, J. L. (1991), Discerning the forest from the trees: an essay on scaling canopy stomatal conductance, Agric. Forest Meteorol. 54: 197-226.

Bingham, G. E., Gillespie, C. H., and McQuaid, J. H. (1978), Development of a miniature, rapid response $\mathrm{CO}_{2}$ sensor, Report UCRL-52440, Lawrence Livermore National Laboratory.

Brutsaert, W. (1984), Evaporation into the Atmosphere, Reidel, Dordrecht.

Chamberlain, A. C. (1966), Transport of gases to and from grass and grass-like surfaces, Proc. Roy. Soc. London A 290:236-265.

Chamberlain, A. C. (1968), Transport of gases to and from surfaces with bluff and wave-like roughness elements, Quart. J. Roy. Meteorol. Soc. 94:318-332.

Dave, J.lV. (1978), Extensive data sets of diffuse radiation in realistic atmospheric models with aerosols and common absorbing gases, Solar Energy 21:361-369.

Fraser, R. S., Ferrare, R. A., Kaufman, Y. J., and Mattoo, S. (1989), Algorithm for atmospheric corrections of aircraft and satellite imagery, NASA Technical Memorandum 100751, 106 pp.

Garratt, J. R., and Hicks, B. B. (1973), Momentum, heat and water vapour transfer to and from natural and artificial surfaces, Quart. J. Roy. Meteorol. Soc. 99:680-687.

Halthore, R., Brugge, C., and Markham, B. (1990), Aerosol optical thickness measurements during FIFE '89, in Preprint Volume of the Symposium on the First ISLSCP Field Experiment (FIFE), 7-9 Feb. 1990, Anaheim, CA, AMS, Boston, pp. 121-125.

Jackson, R. D., Moran, M. S., Slater, P. N., and Biggar, S. F. (1987), Field calibration of reference reflectance panel, Remote Sens. Environ. 25:145-158.

Jarvis, P. G. (1976), The interpretation of the variations in leaf water potential and stomatal conductance found in canopies in the field, Phil. Trans. Roy. Soc. London Ser. B. 273:593-610.

Jarvis, P. G., James, G. B., and Landsberg, J. J. (1976), Coniferous forest, in Vegetation and the Atmosphere, Vol. 2, Case Studies (J. L. Monteith, Ed.), Academic, New York, pp. 171-240.

Kaimal, J. C. (1975), Sensors and techniques for direct measurement of turbulent fluxes and profiles in the atmospheric surface layer, Atmos. Technol. 7:7-14.

Kanemasu, E. T., Wesely, M. L., Hicks, B. B., and Heilman, J. L. (1979), Techniques for calculating energy and mass fluxes, in Modification of the Aerial Environment of Crops (B. L. Barfield and J. F. Gerber, Eds.), Am. Soc. of Agric. Eng., St. Joseph, MI.
Kim, J., and Verma, S. B. (1990a), Components of surface energy balance in a temperate grassland ecosystem, Boundary-Layer Meteorol. 51:401-417.

Kim, J., and Verma, S. B. (1990b), Carbon dioxide exchanges in a temperate grassland ecosystem, Boundary-Layer Meteorol. 52:135-149.

Kim, J., and Verma, S. B. (1991), Modeling canopy stomatal conductance in a temperature grassland ecosystem, Agric. Forest Meteorol. 55:149-166.

Knapp, A. K. (1985), Effect of fire and drought on the ecophysiology of Andropogon gerardii and Panicum virgatum in a tallgrass prairie, Ecology 66:1309-1320.

Kniezys, F. X., Shettle, E. P., Gallery, W. O., et al. (1988), Atmospheric Transmittance/Radiance: Computer Code LOWTRAN-7, AFGL-TR88-0177, Air Force Geophysics Lab, Hanscom AFB, MA.

Kucera, C. L., and Kirkham, D. R. (1971), Soil respiration studies in tallgrass prairie in Missouri, Ecology 52:912915.

Lohammar, T., Larsson, S., Lindner, S., and Falk, S. (1980), FAST-simulation models of gaseous exchange in Scots pine, in Structure and Function of Northern Coniferous Forests-An Ecosystem Study, Ecol. Bull. 32:505-523.

Markham, B. L., Wood, Jr., F. M., and Ahmad, S. P. (1988), Radiometric calibration of the reflective bands of NS001thematic mapper simulator (TMS) and modular multispectral radiometers (MMR), in Proc. of SPIE Tech. Symp., 4-8 April 1988, Orlando, FL.

Monteith, J. L. (1965a), Evaporation and environment, in The State and Movement of Water in Living Organisms (G. E. Fogg, Ed.), Academic, New York, pp. 205-234.

Monteith, J. L. (1965b), Light distribution and photosynthesis in field crops, Ann. Bot. N. S. 113:17-37.

Monteith, J. L. (1977), Climate and the efficiency of crop production in Britain, Phil. Trans. Roy. Soc. London B281: 277-294.

Owen, P. R., and Thomson, W. R. (1963), Heat transfer across rough surfaces, J. Fluid Mech. 15:321-334.

Polley, H. W., Norman, J. M., Arkebauer, T. J., Walter-Shea, E. A., Greegor, Jr., D. H., and Bramer, C. (1992), Gas exchange of Andropogon gerardii Vitman, Panicum virgatum L., and Sorghastrum nutans (L.) Nash in a tallgrass prairie, J. Geophys. Res., forthcoming.

Schuepp, P. H., Leclerc, M. Y., MacPherson, J. I., and Desjardins, R. L. (1990), Footprint prediction of scalar fluxes from analytical solutions of the diffusion equation, Boundary-Layer Meteorol. 55:355-373.

Sellers, P. J. (1985), Canopy reflectance, photosynthesis and transpiration, Int. J. Remote Sens. 6(8):1335-1372.

Sellers, P. J. (1987), Canopy reflectance, photosynthesis, and transpiration. II. The role of biophysics in the linearity of their interdependence, Remote Sens. Environ. 21:143183.

Stewart, J. B. (1988), Modelling surface conductance of pine forest, Agric. For. Meteorol. 43:19-35. 
Thom, A. S. (1972), Momentum, mass, and heat exchange of vegetation, Quart. J. Roy. Meteorol. Soc. 98:124-134.

Thom, A. S. (1975), Momentum, mass, and heat exchange of plant communities, in Vegetation and the Atmosphere (J. L. Monteith, Ed.), Academic, New York, Vol. 1, pp. 57-109.

Tucker, C. J., Holben, B. N., Elgin, J. H., and McMurtrey, E. (1981), Remote sensing of total dry matter accumulation in winter wheat, Remote Sens. Environ. 11:171-190.

Verma, S. B. (1989), Aerodynamic resistances to transfers of heat, mass and momentum, in Estimation of Areal Evapotranspiration (T. A. Black, D. L. Spittlehouse, M. D. Novak, and D. T. Price, Eds.), International Association of Hydrological Sciences Publication No. 177, pp. 13-20.

Verma, S. B. (1990), Micrometeorological methods for mea- suring surface fluxes of mass and energy, Remote Sens. Rev. 5:99-115.

Verma, S. B., Kim, J., and Clement, R. J. (1992), Momentum, water vapor and carbon dioxide exchange at a centrally located prairie site during FIFE, J. Geophys. Res. forthcoming.

Wesely, M. L., and Hicks, B. B. (1977), Some factors that affect the deposition rates of sulfur dioxide and similar gases on vegetation, J. Air Pollution Control Assoc. 27: 1110-1115.

Wrigley, R. C., Spanner, M. A., Slye, R. E., Pueschel, R. F., and Livingston, J. M. (1990), Optical depth measurements and atmospheric correction of remotely sensed data for FIFE, in Preprint Volume of the Symposium on the First ISLSCP Field Experiment (FIFE), 7-9 Feb. 1990, Anaheim, CA, AMS, Boston, pp. 127-134. 